through sensors placed on satellites. ${ }^{5}$ Recent years brought the launch of publicly supported Sentinel satellites carrying imaging sensors with the greatly improved-in comparison with their antecedents-resolution of $10 \mathrm{~m},{ }^{6}$ as well as commercial satellites with an even higher resolution. ${ }^{7}$ The new capability, aided by the establishment of open-access infrastructure for processing the high-resolution images 8,9 and the recent revolutionary progress in artificial intelligence (AI), ${ }^{10}$ now makes it feasible to obtain the information at low cost and in near-to-real time.

In this brief, we discuss the use of satellite images to provide information about agricultural production in LMICs, and we comment on research challenges and opportunities. We highlight the near-term potential of the methodology in the context of Rwanda, a country in sub-Saharan Africa whose government has recognized early the value of information technology in its strategic planning for food security and sustainability. ${ }^{11,12}$

\section{From Data to Information}

Figure 1 is a conceptual schematic of the process flow for extracting information about agricultural production from satellite images. The methodology shown in Figure 1 is a collective outcome of the work of many research groups and organizations worldwide over the last three decades and is the subject of extensive literature (Atzberger ${ }^{13}$ provides a good introduction). The inputs are data embedded in satellite images. Optical images represent reflectance of light (solar radiation) from the Earth's surface as a function of the wavelength of the light. For crops, this spectral reflectance is determined by the plant's biophysical and biochemical properties, such as the leaf area, biomass, chlorophyll content, water content, and canopy structure, as well as external factors such as background soil. ${ }^{14}$ Synthetic aperture radar (SAR) images represent reflectance of electromagnetic radiation in the microwave range. For crops, this reflectance is primarily a function of the canopy architecture such as the size, shape, and orientation of canopy components (leaves, stalks, fruit); the dielectric properties of the crop canopy; and the cropping characteristics such as plant density and row direction. ${ }^{15}$ The potential output of a collective analysis of the optical and/or SAR satellite images is information about crop acreage, crop health (including incipient damage from pests; see, e.g., Zhang et al. ${ }^{16}$ ), and crop yield. Typically, satellite sensors acquire reflectance information for specific wavelengths (bands). Continuing development in sensor technologies is increasing the number of bands and their combined spectral range, enhancing the ways in which satellite images can be used to create knowledge products.

The information extraction process, illustrated in the bottom box of Figure 1, relies on algorithms (models) that are developed (trained) using data representing the relevant

Figure 1. Data acquired by imaging sensors placed on satellites can provide valuable information on crop acreage, health, and yields

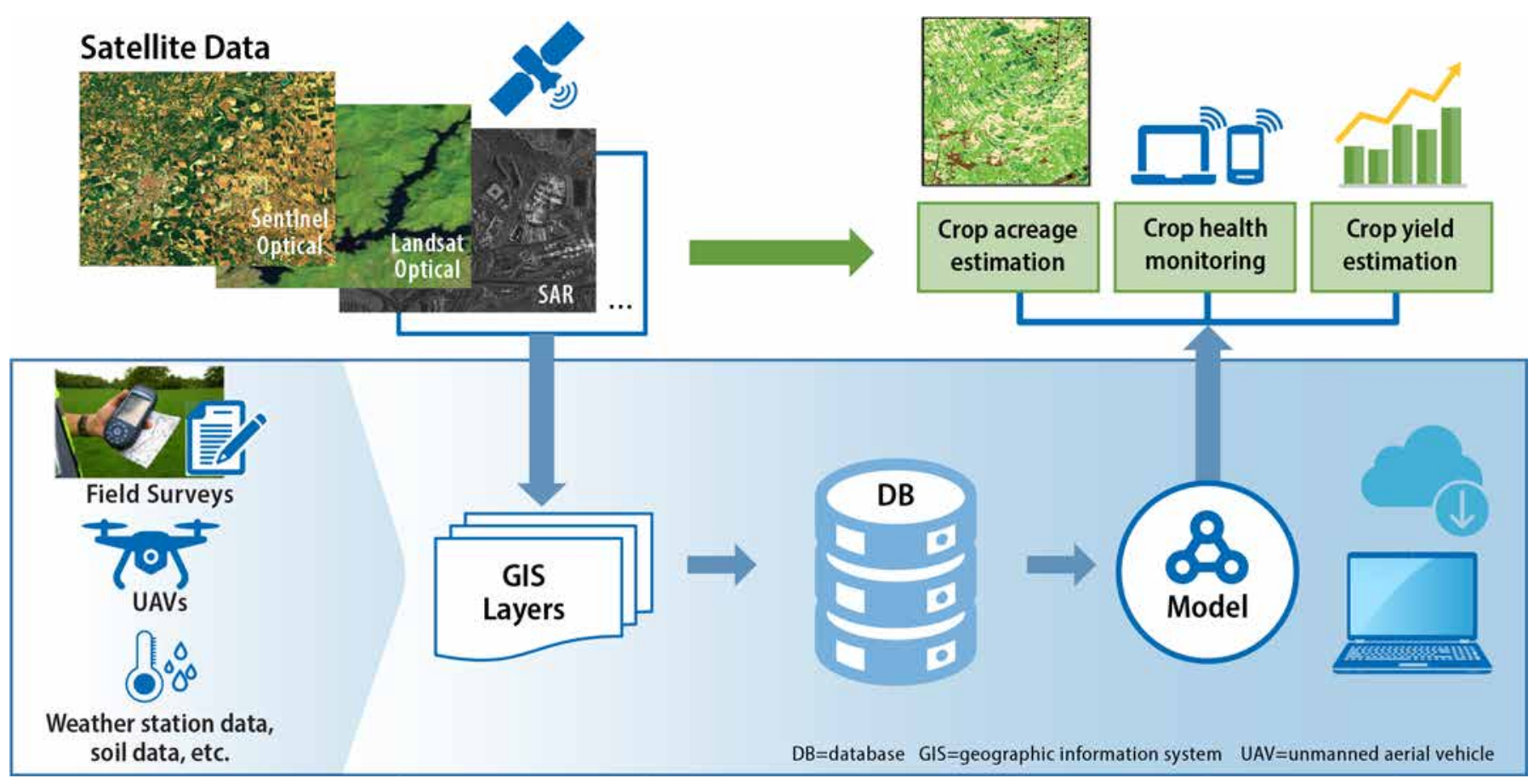


"ground-truth" (i.e., ground reference data ${ }^{17}$ ). The groundtruth data are obtained in selected locations using field surveys and, more recently, are augmented by unmanned aerial vehicles (UAVs). ${ }^{18}$ Using auxiliary data, such as weather station reports, can increase accuracy of the algorithms. ${ }^{19}$ Although deep machine-learning models are increasingly being used for information extraction, ${ }^{20}$ more traditional parametric methods, illustrated later in this brief, are still commonly applied and remain a standard for benchmarking classification experiments. ${ }^{21}$

Once fully developed, the AI models depicted in Figure 1 typically function on their own - they do not require a continuous ground-truth data stream. They do need to be re-parameterized whenever there are substantial changes in biophysical conditions of the agricultural production (e.g., the introduction of new cultivars or significant changes in weather patterns). The models extract information from satellite images as the images become available, resulting in dynamic maps that not only capture the state at a specific time but can also be used to monitor change-a feature particularly important for agriculture, where information is worth little if it comes too late.

Although the basic concepts shown in Figure 1 were established as early as the 1970s and the methodology has been implemented since then in an increasingly sophisticated way to provide a variety of agricultural information products at the global and continent scales, ${ }^{22,23}$ only recently have the satellite image resolution, data processing capability and cost of the data acquisition and processing reached the levels that make it feasible to characterize regional and even field-scale agricultural production in the situation where smallholder farms dominate, as is often the case in developing countries. The regional and field-scale, as contrasted with a global- or continental-scale, assessment is critical, given the high spatial variability of agricultural practices in smallholder systems, compounding the variability of climatic and soil conditions.

The seminal work of Burke and Lobell tracked maize grown on smallholder farms in western Kenya, using a combination of high-resolution satellite imagery and field survey data. ${ }^{24}$ They constructed a crop acreage map for maize by using field data collected on both maize and nonmaize crops to train an AI model-a crop classifier-that can distinguish maize pixels from nonmaize ones. Then they applied a regression model that related data embedded in satellite images to fieldmeasured yields to produce a field-scale maize yield forecast that they found to be roughly as accurate as the traditional field survey measures. These results indicate a substantial nearterm potential to generate useful datasets on productivity in smallholder systems. ${ }^{24}$

\section{Use of UAVs for Ground-Truth Collection}

Modern technology can further simplify the task of developing the models by opening doors to using UAVs in ground-truth data collection. A fixed-wing UAV can cover an area of 100 ha in a flight lasting less than 1 hour, obtaining an aerial image with a resolution on the order of centimeters, in which each pixel is geo-referenced-a much faster, less costly, and typically more accurate process than is possible on the ground. ${ }^{18}$

As an example, Figure 2 shows georeferenced aerial images of approximately 80 ha of land in the Kamonyi district of Rwanda, obtained in late October 2018 using an eBee Plus UAV, manufactured by SenseFly and operated by a Rwandan UAV services company, Charis Unmanned Aerial Solutions. The UAV includes a built-in data-link connection to a base station, which makes it possible to georeference the images with the accuracy of $10 \mathrm{~cm}$ in both horizontal and vertical directions. For this flight, the eBee UAV was equipped with

\section{Figure 2. Georeferenced aerial images of agricultural land in the Kamonyi district of Rwanda from an unmanned aerial vehicle flight}
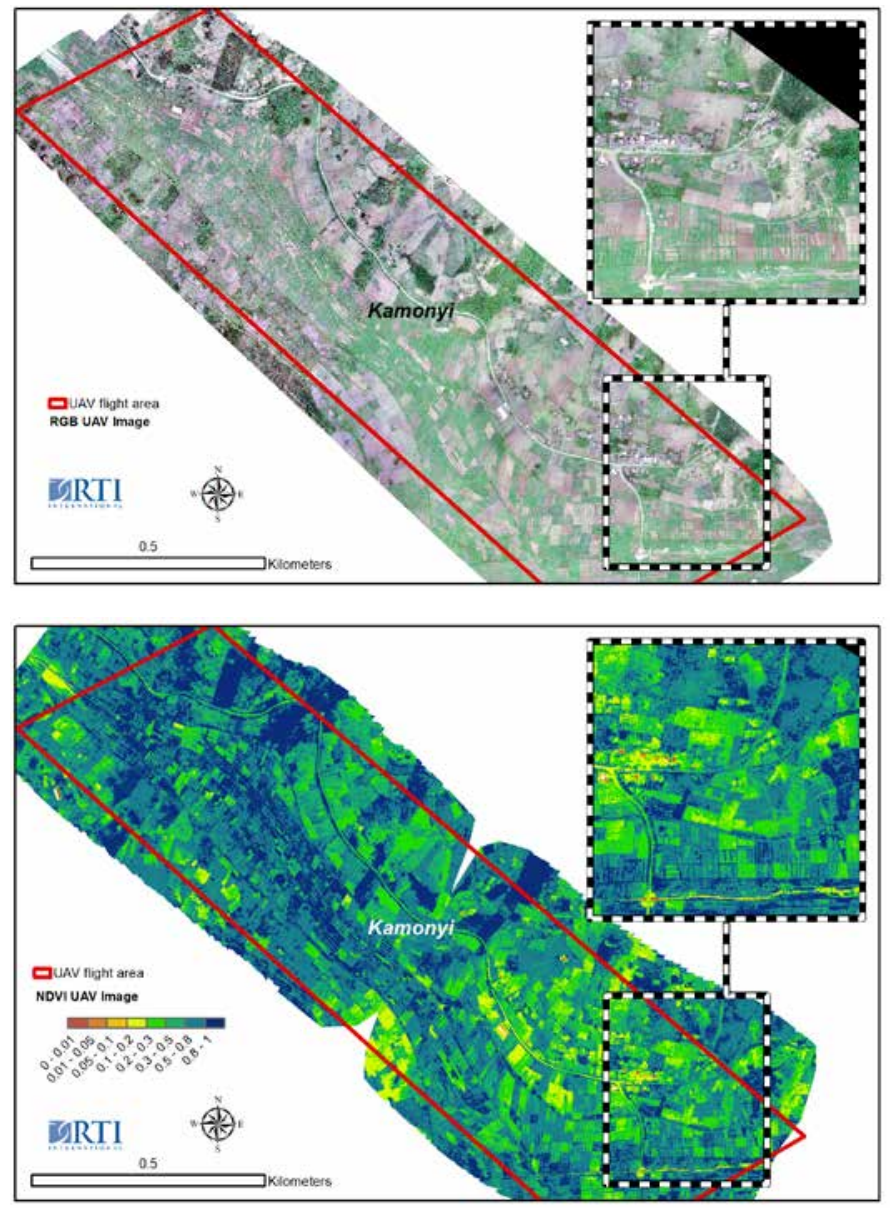

Figure $2 a$ is the image obtained by the RGB camera. Figure $2 b$ is a map of the normalized-difference vegetation index, derived from images obtained by the multispectral camera. 
SenseFly S.O.D.A. RGB [red, green, and blue] and Sequoia multispectral cameras. Figure $2 \mathrm{a}$ is the image obtained by the RGB camera at $3 \mathrm{~cm}$ resolution. Figure $2 \mathrm{~b}$ shows a map of the same area that is derived from an image obtained by the multispectral camera. Specifically, the map shows values of the normalized-difference vegetation index (NDVI), a simple but effective index for quantifying the greenness of vegetation and other land cover. NDVI can be calculated for each pixel using the equation NDVI $=\left(\rho_{\mathrm{NIR}}-\rho_{\mathrm{R}}\right) /\left(\rho_{\mathrm{NIR}}+\rho_{\mathrm{R}}\right)$, where $\rho_{\mathrm{NIR}}$ and $\rho_{\mathrm{R}}$ represent the surface reflectance in the near-infrared and red bands of the optical spectrum, respectively. ${ }^{25}$ The index normalizes green-leaf scattering in the near-infrared band and chlorophyll absorption in the red band.

By inspecting UAV-acquired high-resolution RGB images, like the one in Figure 2a, a human analyst can create a groundtruth dataset that e.g. identifies the type of land cover. For example, it might be of interest to classify the land cover into two basic categories: category 1, "Active Agriculture," corresponding to land under cultivation, and category 2 , "Nonactive Agriculture," corresponding to land with no/little plant growth or the land occupied by buildings and other impervious structures in otherwise agricultural areas. From the inspection of the UAV images shown in Figure 2, one can then attempt to correlate the land cover category with a range of NDVI values. Using NDVI threshold values, a computer program can then automatically classify a much larger area using a satellite image. Figure 3 shows results of such simple classification model applied to the multispectral image of the whole Kamonyi district acquired by the Sentinel-2 satellite within a few days of the UAV flight. In the image, nonagricultural areas-like urban areas, forests, or water bodies, and pixels covered by clouds-were masked.

We estimated the accuracy of the classification by testing the model against a ground-truth dataset, again extracted from UAV images. For this test dataset, we selected different pixels (locations) than the ones that were used to develop the model. Again, a human analyst inspected UAV images and identified the land cover category. We found that the model correctly classified satellite image pixels in 88 percent of the cases.

From the map shown in Figure 3, one can estimate the area of agricultural land that was under cultivation at the time when the satellite image was obtained. After applying a correction factor for the presence of clouds, this active area was calculated to be approximately 35,000 hectares ( $35 \mathrm{kha}$ ). This number is close to our active area estimate of $36.5 \mathrm{kha}$ from the Seasonal Agricultural Survey for Season A 2019, published by the National Institute of Statistics of Rwanda. ${ }^{26}$

By applying AI techniques to satellite images acquired at different points in time-in different years, seasons, and during a growing season-one can track changes in the extent of agricultural cultivation. This type of information can also be used to monitor the start of the planting season to provide early warning of, for example, weather-related delays and accelerate potential interventions.

\section{Future Work}

District-scale cropland-extent maps are starting points to develop higher-level information products. In our work pertaining to Rwanda, we are developing models to identify land cultivated by a specific crop and extend this classification to the whole country. For Rwanda, priority food crops are maize, beans, cassava, Irish potato, rice, and wheat. ${ }^{27} \mathrm{To}$ develop an AI model that distinguishes, for example, maize pixels from nonmaize pixels, we need a training dataset comprising multispectral satellite images of fields cultivated with maize and a training dataset composed of multispectral images of other type of crops in cultivation in a given time period. ${ }^{24}$ The use of UAVs as high-throughput ground-truth collectors enables the required large training-data volume. We have obtained ground-truth data in several different ecological zones in Rwanda to capture variations in the spectral

\section{Figure 3. Map of the Kamonyi district with the binary classification into active agricultural land and nonactive agricultural land}

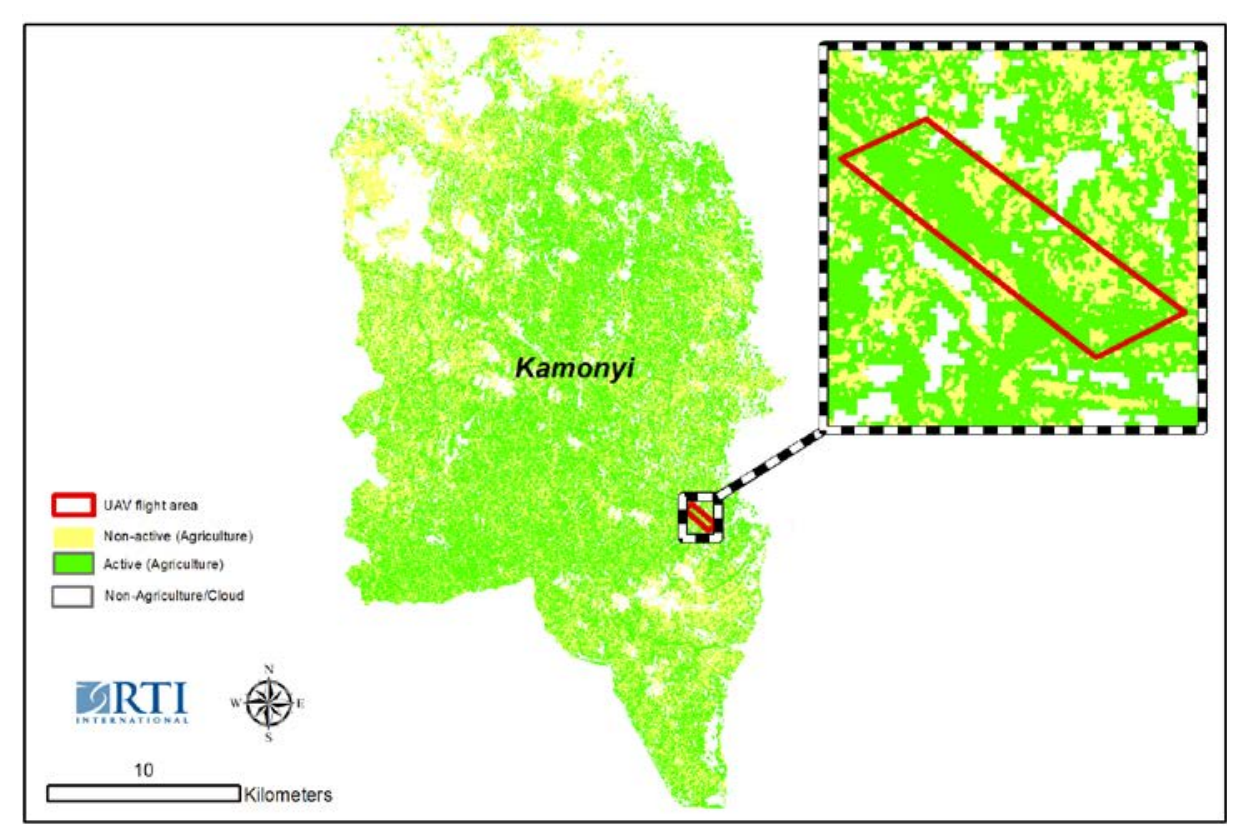


signatures of maize with soil and weather conditions and at several times during the growing season to obtain time-series data to increase the accuracy of the crop classification. ${ }^{28-32}$

Longer-term objectives include the development of AI models for forecasting yields of strategic crops and the timing of harvests, based on changes in physical characteristics of the plants reflected in multispectral satellite images collected during the growing season.

\section{Challenges and Opportunities}

Acquiring satellite-driven data has inherent limitations. One of the most important ones is the effect of clouds. Clouds block images acquired using light in the visible and infrared ranges. For Rwanda, cloud cover during the two main growing seasons is significant. For example, we found that only 10 percent of the Sentinel-2 35-MRT image tiles (covering one-third of Rwanda), available for 2018 (1/1/2018 to 12/04/2018) were cloud free (cloud free describes an image in which fewer than 5 percent of pixels are blocked by clouds). The partial solution is the process of mosaicking and filling, in which a composite image is formed using cloud-free portions of the tiles acquired on different dates. SAR satellite systems that use electromagnetic radiation that is not absorbed by clouds offer the potential for additional solutions. The work on the development of a robust SAR image interpretation methodology for agricultural applications is progressing. ${ }^{33}$

There are also challenges and opportunities inherent in the type of agricultural system. For Rwanda, many smallholder farmers plant more than one crop on the same parcel of land. The intercropping may change optical and SAR signals from the plot as compared with the main crop and influence the accuracy of land classification, crop monitoring, and yield forecast models. ${ }^{34}$ Plots are also very small and may require satellite images with the resolution better than $10 \mathrm{~m}$. However, one opportunity for better crop classification in Rwanda is that there are many consolidated land-use areas where only one crop is planted in a large area, making it more conducive to identification via machine learning.

Like any process of acquiring and processing data, extracting information through automated, computer-driven analysis of satellite images comes with uncertainty. ${ }^{35-37}$ The most direct way of assessing the uncertainty is to test the model predictions against a ground-truth test dataset, as shown in an earlier example. A way to limit the uncertainty and increase the model robustness is to increase the quantity and quality of ground-truth training data, acquisition of which is a major bottleneck. We believe that the increasing availability of UAVs will accelerate data collection, whereas ongoing improvements in open-source data processing platforms will continue to decrease the burden of data preprocessing and further increase the pace of the development of analytical tools.

\section{Impact}

The agricultural sector is the backbone of Rwanda's economyit contributes more than 33 percent of GDP and is the biggest employer. ${ }^{12}$ The country's food demand continues to grow, reflecting fast population growth, and agricultural productivity and total production need to increase dramatically to meet the demand. Satellite systems have the near-term potential to provide stakeholders in countries where smallholder systems dominate with information on crop production, status, and yield that is timely, covers large areas, captures spatial and temporal detail, and can be obtained at a low cost. Based on the information, stakeholders will be better prepared to make intervention decisions earlier in the growing season if needed and will have tools to assess long-term impacts of policies and investments. The information could also be used to detect pockets of rapidly increasing food insecurity, sparking a response that could alleviate political instability in areas that rely heavily on agricultural production. Continued public and commercial support is needed, not only for improvements in the satellite infrastructure and the development of robust models for information extraction, but also for implementing the new data analysis tools to address development challenges. ${ }^{38}$ United Nations Pulse Laboratory Kampala provides an example of an effective initiative. ${ }^{39}$ The continued support will pay dividends for food security and sustainability.

\section{References}

1. The State of Food Security and Nutrition in the World. Building climate resilience for food security and nutrition. Rome (Italy): FAO, IFAD, UNICEF, WFP and WHO; 2018.

2. Foley JA, Ramankutty N, Brauman KA, Cassidy ES, Gerber JS, Johnston M, Mueller ND, O’Connell C, Ray DK, West PC, Balzer C, Bennett EM, Carpenter SR, Hill J, Monfreda C, Polasky S, Rockström J, Sheehan J, Siebert S, Tilman D, Zaks DPM. (2011). Solutions for a cultivated planet. Nature. 2011;478(7369):337-42. https://doi.org/10.1038/nature10452

3. Tilman D, Balzer C, Hill J, Befort BL. Global food demand and the sustainable intensification of agriculture. Proc Nat Acad Sci USA. 2011;108(50): 20260-4. https://doi.org/10.1073/ pnas. 1116437108

4. Bock ME, Kirkendall NJ, editors. Improving crop estimates by integrating multiple data sources. Washington (DC): The National Academies Press; 2017.

5. Pixalytics. How many satellites are orbiting the Earth in 2018 ? 2018 Aug 22. Available from: https://www.pixalytics.com/satsorbiting-the-earth-2018/ 
6. European Space Agency. SENTINEL Overview. 2019. Available from: https://earth.esa.int/web/sentinel/user-guides/sentinel-2$\mathrm{msi} /$ resolutions/radiometric

7. Satellite Imaging Corporation. Satellite sensors. 2017. Available from: https://www.satimagingcorp.com/satellite-sensors

8. Gorelick N, Hancher M, Dixon M, Ilyushchenko S, Thau D, Moore R. Google Earth Engine: Planetary-scale geospatial analysis for everyone. Remote Sensing Environ. 2017;202:18-27. https://doi.org/10.1016/j.rse.2017.06.031

9. Sentinel-2. The Sen2-Agri System. 2018 Aug 10. Available from: http://www.esa-sen2agri.org/

10. Wikipedia. History of artificial intelligence. 2019 May 21. Available from: https://en.wikipedia.org/wiki/History_of_ artificial_intelligence

11. Republic of Rwanda, Ministry of Agriculture and Animal Resources. Strategic plan for the transformation of agriculture in Rwanda-Phase II (PSTA II). Final report. 2009 Feb. Available from: http://www.minagri.gov.rw/fileadmin/user_upload/ documents/RWANDA_SAKSS/PSTA_II_2008-12_pdf

12. Republic of Rwanda, Ministry of Agriculture and Animal Resources. National ICT4RAg Strategy (2016-2020). 2016. Available from: http://www.minagri.gov.rw/fileadmin/ user_upload/documents/policies_and_strategy/ICT4RAg_ STRATEGIC_PLAN_2016-2020_final_final_3_.pdf

13. Atzberger C. Advances in remote sensing of agriculture: context description, existing operational monitoring systems and major information needs. Remote Sensing. 2013;5(2):949-81. https:// doi.org/10.3390/rs5084124

14. Jensen JR. Remote sensing of the environment. 2nd ed. Upper Saddle River, NJ: Pearson Prentice Hall; 2007.

15. McNairn H, Champagne C, Shang J, Holmstrom D, Reichert G. (Integration of optical and Synthetic Aperture Radar (SAR) imagery for delivering operational annual crop inventories. ISPRS J Photogrammetry Remote Sensing. 2009;64(5):434-49. https:// doi.org/10.1016/j.isprsjprs.2008.07.006

16. Zhang J, Huang Y, Yuan L, Yang G, Chen L, Zhao C. Using satellite multispectral imagery for damage mapping of armyworm (Spodoptera frugiperda) in maize at a regional scale. Pest Manage Sci. 2016;72(2):335-48. https://doi.org/10.1002/ps.4003

17. Congalton RG, Green K. (2009). Assessing the accuracy of remotely sensed data. Boca Raton, FL: CRC Press, Taylor \& Francis Group.

18. Koeva M, Muneza M, Gevaert C, Gerke M, Nex F. Using UAVs for map creation and updating. A case study in Rwanda. Survey Rev. 2018;50(361):312-25. https://doi.org/10.1080/00396265.2016 .1268756
19. Cai XL, Sharma BR. Integrating remote sensing, census and weather data for an assessment of rice yield, water consumption and water productivity in the Indo-Gangetic river basin. Agricultural Water Manage. 2010;97(2):309-16. https:/doi. org/10.1016/j.agwat.2009.09.021

20. Kamilaris A, Prenafeta-Boldu FX. Deep learning in agriculture: a survey. Computers Electronics Agriculture. 2018;147:70-90. https://doi.org/10.1016/j.compag.2018.02.016

21. Maxwell AE, Warner TA, Fang F. Implementation of machinelearning classification in remote sensing: An applied review. Int J Remote Sensing. 2018;39(9):2784-817. https://doi.org/10.1080/01 431161.2018.1433343

22. Xiong J, Thenkabail PS, Tilton JC, Gumma MK, Teluguntla P, Oliphant A, Congalton RG, Ydav K, Gorelick N. Nominal 30-m cropland extent map of continental Africa by integrating pixel-based and object-based algorithms using Sentinel-2 and Landsat-8 data on Google Earth Engine. Remote Sensing. 2017;9(10):1065. https://doi.org/10.3390/rs9101065

23. Becker-Reshef I, Justice C, Sullivan M, Vermote E, Tucker C, Anyamba A, Small J, Pak E, Masuoka E, Schmaltz J, Hansen M, Pittman K, Birkett C, Williams D, Reynolds C, Doorn B. Monitoring global croplands with coarse resolution earth observations: the Global Agriculture Monitoring (GLAM) project. Remote Sensing. 2010;2(6):1589-1609. https://doi. org/10.3390/rs2061589

24. Burke M, Lobell DB. Satellite-based assessment of yield variation and its determinants in smallholder African systems. Proc Nat Acad Sci USA. 2017;114(9):2189-94. https://doi.org/10.1073/ pnas. 1616919114

25. Candiago S, Remondino F, De Giglio M, Dubbini M, Gattelli M. Evaluating multispectral images and vegetation indices for precision farming applications from UAV images. Remote Sensing. 2015;7(4):4026-47. https://doi.org/10.3390/rs70404026

26. National Institute of Statistics of Rwanda. Seasonal Agricultural Survey. Season A 2019 report. 2019 Apr. Available from: http:// www.statistics.gov.rw/publication/seasonal-agricultural-surveyreport-season-2019

27. Republic of Rwanda, Ministry of Agriculture and Animal Resources. Strategies for sustainable crop intensification in Rwanda. 2011. Available from: http://www.minagri.gov.rw/ fileadmin/user_upload/documents/CIP/CIP_Strategies_2011.pdf

28. Lobell DB, Asner GP. Cropland distributions from temporal unmixing of MODIS data. Remote Sensing Environ. 2004;93(3):412-22. https://doi.org/10.1016/j.rse.2004.08.002

29. Brown JC, Kastens JH, Coutinho AC, Victoria DD, Bishop CR. Classifying multiyear agricultural land use data from Mato Grosso using time-series MODIS vegetation index data. Remote Sensing Environ. 2013;130:39-50. https://doi.org/10.1016/j. rse.2012.11.009 
30. Murthy CS, Raju PV, Badrinath KVS. Classification of wheat crop with multi-temporal images: Performance of maximum likelihood and artificial neural networks. Int J Remote Sensing. 2003;24(23):4871-90. https://doi. org/10.1080/0143116031000070490

31. Wardlow BD, Egbert SL. Large-area crop mapping using timeseries MODIS $250 \mathrm{~m}$ NDVI data: An assessment for the US Central Great Plains. Remote Sensing Environ. 2008;112(3), 1096-1116. https://doi.org/10.1016/j.rse.2007.07.019

32. Gómez C, White JC, Wulder MA. Optical remotely sensed time series data for land cover classification: a review. ISPRS J Photogrammetry Remote Sensing. 2016;116:55-72. https://doi. org/10.1016/j.isprsjprs.2016.03.008

33. Hosseini M, McNairn H. Using multi-polarization C- and L-band synthetic aperture radar to estimate biomass and soil moisture of wheat fields. Int J Appl Earth Observation Geoinformation. 2017;58:50-64. https://doi.org/10.1016/j.jag.2017.01.006

34. Bégué A, Arvor D, Bellon B, Betbeder J, de Abelleyra DPD, Ferraz R, Lebourgeois V, Lelong C, Simões M, Verón SR. Remote sensing and cropping practices: a review. Remote Sensing. 2018;10(1), 99. https://doi.org/10.3390/rs10010099

35. Giacco F, Thiel C, Pugliese L, Scarpetta S, Marinaro M. Uncertainty analysis for the classification of multispectral satellite images using SVMs and SOMs. IEEE Trans Geosci Remote Sensing. 2010;48(10):3769-79. https://doi.org/10.1109/ TGRS.2010.2047863
36. Lu D, Weng Q. A survey of image classification methods and techniques for improving classification performance. Int J Remote Sensing. 2007;28(5):823-70. https://doi. org/10.1080/01431160600746456

37. Foody GM, Atkinson PM, editors. Uncertainty in remote sensing and GIS. Chichester, England: John Wiley \& Sons, Ltd.; 2002.

38. Crouch L. A relevant data revolution for development. RTI Press Publication No. PB-0007-1506. Research Triangle Park, NC: RTI Press; 2015. https://doi.org/10.3768/rtipress.2015. pb.0007.1506

39. United Nations Global Pulse. Pulse Lab Kampala. 2018. Available from: https://www.unglobalpulse.org/kampala 


\begin{abstract}
About the Authors
Dorota S. Temple, PhD, is Distinguished Fellow in Electronics and Applied Physics at RTI International.
\end{abstract}

Jason S. Polly, BS, is a research geospatial scientist at RTI International.

Meghan Hegarty-Craver, PhD, is a research biomedical engineer at RTI International.

James I. Rineer, MS, is a senior GIS architect at RTI International.

Daniel Lapidus, MA, is a research economist at RTI International.

Kemen Austin, PhD, is a research economist at RTI International.

Katherine P. Woodward, MSPH, is an environmental scientist at RTI International.

Robert H. Beach, PhD, is Fellow in Economics at RTI International.

\section{RTI Press Associate Editor}

Jeremiah Ngondi

\section{Acknowledgments}

We gratefully acknowledge the financial support of RTI International through its Grand Challenge Initiative. We have benefited greatly from discussions with Melanie Bittle and other members of the RTI PSDAG project, stakeholders in the Government of Rwanda, United States Agency for International Development, United Kingdom Department for International Development, European Union, World Bank, UN Food and Agriculture Organizations and many nongovernment organizations operating in Rwanda. Noel Ujeneza, as well as Mads Knudsen from Vanguard Economics have also provided critical support to advance this analysis.
RTI Press Research Briefs and Policy Briefs are scholarly essays on policy, methods, or other topics relevant to RTI areas of research or technical focus.

RTI International, 3040 East Cornwallis Road, PO Box 12194 Research Triangle Park, NC 27709-2194 USA

+1.919.541.6000_rtipress@rti.org_www.rti.org

(c) RTI International. RTI International is a registered trademark and a trade name of Research Triangle Institute. The RTI logo is a registered trademark of Research Triangle Institute.

(c) (i) $(-)$ This work is distributed under the terms of a Creative Commons c. Attribution-NonCommercial-NoDerivatives 4.0 license (CC BY-NC-ND), a copy of which is available at https://creativecommons.org/ licenses/by-nc-nd/4.0/legalcode

www.rti.org/rtipress 